\title{
Dynamical downscaling for the southwest of Western Australia using the WRF modelling system
}

\author{
J. Kala ${ }^{\text {a }}$, B. J. Evans ${ }^{\text {a }}$, T. J. Lyons ${ }^{\text {a }}$, I. J. Foster ${ }^{\text {b }}$ \\ ${ }^{a}$ School of Environmental Science, Murdoch University, Murdoch, Western Australia, 6150 \\ ${ }^{\mathrm{b}}$ Department of Agriculture and Food, Bentley, Western Australia, 6102 \\ Email: J.Kala@murdoch.edu.au
}

\begin{abstract}
The southwest of Western Australia (SWWA) is a region of significant cereal production, with the main crops being winter grown wheat and barley. The most important factors influencing wheat growth and production are temperature extremes and precipitation, and hence, it is critical to have an understanding of how these environmental factors have changed in the past, and how they are likely to change in the future. One method of addressing this important research question is by using regional climate models (RCMs) to dynamically downscale re-analysis products and/or output form Global Circulation Models to a fine resolution. One tool which is being increasingly used for this purpose is the Weather Research and Forecasting Model (WRF) Advanced Research (ARW). However, like any modeling system, WRF-ARW requires thorough testing before it is implemented to carry out long-term climate runs. This paper examines the influence of different input data sources, as well as model physics options on simulated precipitation and maximum and minimum temperatures in SWWA by comparing the simulations against an observational gridded dataset.
\end{abstract}

It is found that running WRF3.3 with the $1.0 \times 1.0$ degree National Center for Environmental Prediction Final analysis (NCEP-FNL), as compared to the $2.5 \times 2.5$ degree NCEP / National Center for Atmospheric Research (NCEP/NCAR or NNRP) results in much improved simulations of precipitation and temperatures. Using the National Oceanic and Atmospheric Administration $1.0 \times 1.0$ degree resolution sea surface temperature (SST) dataset does not result in markedly different results as compared to using the NNRP surface skin temperatures as SSTs. Using the Betts-Miller-Jajic (BMJ) scheme for cumulus/convection parameterisation rather than the more widely used Kain-Fritsch (KF) scheme results in slightly higher errors for precipitation, and no marked change in temperatures. The latest version of the Rapid Radiative Transfer Model (RRTMG) is found to result in improved simulations of maximum and minimum temperatures, as compared to the RRTM, Community Atmosphere Model (CAM) 3.0, and Dudhia schemes. Use of the Asymmetric Convective Model as the planetary boundary-layer scheme rather than the more widely used Yonsei University scheme results in over-prediction of maximum and minimum temperatures.

Keywords: Dynamical Downscaling, Regional Climate Modeling, Southwest Western Australia, WRF 


\section{INTRODUCTION}

Cereal production in south-west Western Australia (SWWA) has significant socio-economic implications and the major environmental factors affecting cereal production are temperature extremes and rainfall. Hence an understanding of the current climate of SWWA and how it might change in the future is crucial for the planning and management of SWWA's agriculture. The use of Regional Climate Models (RCMs) such as the Weather Research and Forecasting (WRF) model, Advanced Research WRF (WRF-ARW) (Skamarock et al., 2008), allow for such assessments to be carried out. However, RCMs such as WRFARW can be set-up in a wide variety of configurations, which can lead to significantly different results (Gallus and Bresch, 2006; Lo et al., 2008; Bukovsky and Karoly, 2009; Argzueso et al., 2011; Nauman et al., 2011), and hence it is critical to carefully evaluate the model for specific applications. Accordingly, the aim of this paper is to test the sensitivity of WRF simulated precipitation and temperature maxima and minima to different model configurations for SWWA.

\section{NUMERICAL EXPERIMENTS}

WRF-ARW was run over SWWA from October 2009 to November 2010, with the first two months being model spin-up and not used in the analysis. Two nested grids were used with $50 \mathrm{~km}$ and $10 \mathrm{~km}$ resolution and spanning $5150 \mathrm{~km} \times 4200 \mathrm{~km}$ and $1760 \mathrm{~km} \times 1440 \mathrm{~km}$ respectively. Both grids had 30 vertical levels, with higher vertical resolution within the planetary boundary layer (PBL). Given the relatively long model integration time, spectral nudging was applied to all simulations, to prevent model drift. Nudging was restricted above the PBL and applied to the outer grid only, while the inner was allowed to evolve freely. All simulations used the WRF single-moment 5-class micro-physics scheme, Monin-Obukhov surface layer similarity, and deep soil temperatures were set to a 150-day lagged averaging period. A number of sensitivity tests were carried out as summarised in Table 1. Experiment A is the reference experiment and based on the model parameterisations used by Evans and McCabe (2010) (except that Evans and McCabe (2010) used WRF3.0.1), and all subsequent sensitivity tests only have one setting altered. This experiment uses 6-hourly boundary conditions from the National Center for Environmental Prediction (NCEP) / National Center for Atmospheric Research (NCAR), commonly refereed to as NNRP, which has a resolution of $2.5 \times 2.5$ degrees (Kalnay et al., 1996); the Rapid Radiative Transfer Model (RRTM) for longwave radiation; the Dudhia scheme for shortwave radiation; the Kain-Fritsch (KF) scheme for convection (cumulus physics); and the Yonsei University (YSU) PBL scheme.

Experiment B uses SSTs from the National Oceanic and Atmospheric Administration (NOAA), which provides weekly mean SSTs fields at at a $1.0 \times 1.0$ degree resolution (Reynolds et al., 2002). This was carried out since in Experiment A, WRF uses 6-hourly skin temperatures from the NNRP data as estimates of SSTs. Given the availability of more realistic SST data-sets such as NOAA, it is interesting to investigate if use of the latter results in improved simulations. Experiment $\mathrm{C}$ uses the $1.0 \times 1.0$ degree NCEP Final (NCEP-FNL) Operational Global Data Assimilation System, which has a higher resolution as compared to NNRP, and incorporates more data and includes SSTs, but is only available from July 1999 onwards. This experiment was carried as most studies either use NNRP (e.g., Bukovsky and Karoly, 2009; Evans and McCabe, 2010) or FNL (e.g., Lo et al., 2008), but no comparisons have been made between the two.

Experiment D uses the Betts-Miller-Janjic (BMJ) scheme for convection, rather than KF. The choice of convective scheme can have a strong influence on precipitation simulations (Bukovsky and Karoly, 2009; Argzueso et al., 2011; Nauman et al., 2011). Whilst the majority of studies use the KF scheme (Bukovsky and Karoly, 2009; Evans and McCabe, 2010; Nauman et al., 2011), Argzueso et al. (2011) found the BMJ scheme to perform better for their simulations. Experiments E and F use the new version of the RRTM scheme (RRTMG) and Community Atmosphere Model 3.0 (CAM) radiation schemes respectively for both longwave and shortwave radiation. These experiments were carried out since the RRTMG scheme has not been tested against the other schemes, and the CAM scheme permits modifying greenhouse gas concentrations and their effect on radiation. Finally, experiment $\mathrm{G}$ uses the Asymmetric Convective Model (ACM2) as the PBL scheme, as it has been found to perform better for the simulations of Argzueso et al. (2011). 
Table 1. Summary of numerical experiments carried out

\begin{tabular}{lllllll}
\hline $\begin{array}{l}\text { Experiment } \\
\text { Name }\end{array}$ & $\begin{array}{l}\text { Boundary } \\
\text { Conditions }\end{array}$ & $\begin{array}{l}\text { Longwave } \\
\text { Radiation }\end{array}$ & $\begin{array}{l}\text { Shortwave } \\
\text { Radiation }\end{array}$ & $\begin{array}{l}\text { Convective } \\
\text { Scheme }\end{array}$ & PBL scheme & SST source \\
\hline A & NNRP & RRTM & Dudhia & KF & YSU & NNRP \\
B & NNRP & RRTM & Dudhia & KF & YSU & NOAA \\
C & FNL & RRTM & Dudhia & KF & YSU & NCEP-FNL \\
D & NNRP & RRTM & Dudhia & BMJ & YSU & NNRP \\
E & NNRP & RRTMG & RRTMG & KF & YSU & NNRP \\
F & NNRP & CAM & CAM & KF & YSU & NNRP \\
G & NNRP & RRTM & Dudhia & KF & ACM2 & NNRP \\
\hline
\end{tabular}

\section{OBSERVATIONS AND STATISTICAL ANALYSIS}

Gridded observations of monthly mean precipitation and maximum and minimum temperatures were obtained from the Australia Soil Water Availability (AWAP) project (Raupach et al., 2008, 2009). These data have a resolution of $0.05 \times 0.05$ degrees and have been previously used to evaluate WRF simulations for Eastern Australia (Evans and McCabe, 2010). Following Evans and McCabe (2010), the Bias (B), Mean Absolute Error (MAE), Root Mean Square Error (RMSE), and pattern correlation $\left(\rho_{p}\right)$, are used to evaluate WRF.

$$
\begin{array}{r}
B=\bar{M}-\bar{O} \quad, \quad M A E=\frac{1}{N} \sum_{i=1}^{N}\left(O_{i}-M_{i}\right) \\
R M S E=\sqrt{\frac{1}{N} \sum_{i=1}^{N}\left(O_{i}-M_{i}\right)^{2}} \quad, \quad \rho_{p}=\frac{\sum\left(O_{i}-\bar{O}\right)\left(M_{i}-\bar{M}\right)}{\sqrt{\sum\left(O_{i}-\bar{O}\right)^{2}} \sqrt{\sum\left(M_{i}-\bar{M}\right)^{2}}}
\end{array}
$$

where $\bar{M}$ and $\bar{O}$ are the mean of the modeled and AWAP observations respectively, and $N$ is the number of grid cells. Perfect scores are zero for B and RMSE, and one for $\rho_{p}$.

Comparison of the simulations to the observations was carried out at the seasonal time scale, namely, Summer (December-January-February or DJF), Autumn (March-April-May or MAM), Winter (JuneJuly-August or JJA), and Spring (September-October-November or SON).

\section{RESULTS AND DISCUSSION}

Table 2 shows the summary statistics for the simulations in Table 1 for each of the 4 seasons. Experiment A (the reference) shows that WRF under-predicted precipitation with a negative bias and positive MAE for all seasons. The pattern correlation, $\rho_{p}$ was lowest during DJF (0.01), due to precipitation inland being under-predicted by as much as $40 \mathrm{~mm} / \mathrm{month}$ (not shown). Inland precipitation during DJF is mostly brought about by North-West cloud bands and surface convection, hence these results suggest a lack of convective initiation by the model. Maximum and minimum temperatures were under-predicted during all seasons (negative B and positive MAE), but $\rho_{p}$ was close to one for maximum temperatures for all seasons, while $\rho_{p}$ was only 0.58 for minimum temperatures during JJA. This was due to an underprediction of minimum temperatures in the North-East corner of the domain (not shown).

Experiment B shows that using the NOAA weekly mean SSTs, rather than the 6-hourly surface skin temperatures within the NNRP data-set, does not result in major differences as compared to Experiment A, suggesting the use of surface skin temperatures in NNRP is an adequate approximation to SSTs. Experiment $\mathrm{C}$ shows that using the $1 \times 1$ degrees NCEP-FNL re-analysis data-set as compared to NNRP results in the RMSEs, Bs, and MAEs for precipitation to be lower in magnitude as compared to Experiment A, showing that the forcing data has a significant influence on model results, which is not un-expected. The 
Table 2. RMSE, B, MAE, and $\rho_{p}$ for precipitation (PPT) (mm/month), maximum and minimum temperatures (TMAX and TMIN) $\left({ }^{\circ} \mathrm{C}\right)$ for the experiments in Table 1.

\begin{tabular}{|c|c|c|c|c|c|c|c|c|c|c|c|c|}
\hline Exp & & PPT & & & & TMAX & & & & TMIN & & \\
\hline $\mathrm{A}$ & RMSE & B & MAE & $\rho_{p}$ & RMSE & B & MAE & $\rho_{p}$ & RMSE & B & MAE & $\rho_{p}$ \\
\hline DJF & 12.83 & -9.02 & 9.03 & 0.10 & 3.44 & -3.33 & 3.31 & 0.96 & 2.78 & -2.57 & 2.57 & 0.97 \\
\hline MAM & 23.41 & -21.22 & 21.24 & 0.58 & 1.92 & -1.74 & 1.73 & 0.95 & 2.94 & -2.57 & 2.57 & 0.65 \\
\hline JJA & 20.82 & -17.90 & 17.96 & 0.85 & 2.06 & -1.99 & 1.99 & 0.94 & 3.23 & -2.86 & 2.86 & 0.58 \\
\hline SON & 13.51 & -11.52 & 11.54 & 0.62 & 2.27 & -1.88 & 1.86 & 0.90 & 2.06 & -1.82 & 1.82 & 0.92 \\
\hline B & RMSE & B & MAE & $\rho_{p}$ & RMSE & B & MAE & $\rho_{p}$ & RMSE & B & MAE & $\rho_{p}$ \\
\hline DJF & 12.83 & -8.67 & 8.69 & 0.09 & 3.36 & -3.24 & 3.22 & 0.95 & 2.52 & -2.20 & 2.20 & 0.96 \\
\hline MAM & 23.96 & -21.97 & 21.98 & 0.62 & 1.75 & -1.52 & 1.51 & 0.94 & 3.06 & -2.64 & 2.63 & 0.58 \\
\hline JJA & 20.05 & -16.77 & 16.85 & 0.86 & 2.12 & -2.04 & 2.04 & 0.92 & 3.37 & -2.98 & 2.98 & 0.54 \\
\hline SON & 13.34 & -10.98 & 11.01 & 0.62 & 2.23 & -1.84 & 1.83 & 0.90 & 1.95 & -1.65 & 1.65 & 0.91 \\
\hline $\mathrm{C}$ & RMSE & B & MAE & $\rho_{p}$ & RMSE & B & MAE & $\rho_{p}$ & RMSE & B & MAE & $\rho_{p}$ \\
\hline DJF & 10.29 & 5.03 & -5.02 & 0.33 & 1.93 & -1.74 & 1.73 & 0.96 & 1.87 & 1.67 & -1.67 & 0.97 \\
\hline MAM & 12.88 & -2.53 & 2.56 & 0.34 & 0.86 & -0.54 & 0.54 & 0.96 & 2.06 & 1.92 & -1.92 & 0.94 \\
\hline JJA & 13.17 & 2.87 & -2.82 & 0.81 & 1.45 & -1.23 & 1.23 & 0.95 & 1.54 & 1.23 & -1.22 & 0.84 \\
\hline SON & 7.45 & -2.75 & 2.77 & 0.64 & 1.35 & -1.16 & 1.15 & 0.96 & 1.51 & 1.30 & -1.30 & 0.96 \\
\hline $\mathrm{D}$ & RMSE & B & MAE & $\rho_{p}$ & RMSE & B & MAE & $\rho_{p}$ & RMSE & B & MAE & $\rho_{p}$ \\
\hline DJF & 12.86 & -9.67 & 9.67 & 0.11 & 3.42 & -3.29 & 3.27 & 0.95 & 2.79 & -2.54 & 2.53 & 0.96 \\
\hline MAM & 25.79 & -23.81 & 23.80 & 0.58 & 1.76 & -1.50 & 1.49 & 0.94 & 3.28 & -2.84 & 2.83 & 0.51 \\
\hline JJA & 20.69 & -18.16 & 18.19 & 0.88 & 2.27 & -2.20 & 2.20 & 0.93 & 3.67 & -3.30 & 3.30 & 0.53 \\
\hline SON & 14.33 & -12.61 & 12.61 & 0.59 & 2.02 & -1.66 & 1.65 & 0.90 & 2.05 & -1.80 & 1.80 & 0.92 \\
\hline $\mathrm{E}$ & RMSE & $\bar{B}$ & MAE & $\rho_{p}$ & RMSE & B & MAE & $\rho_{p}$ & RMSE & $\bar{B}$ & MAE & $\rho_{p}$ \\
\hline DJF & 12.75 & -9.17 & 9.18 & 0.10 & 2.57 & -2.37 & 2.35 & 0.95 & 1.92 & -1.67 & 1.66 & 0.97 \\
\hline MAM & 23.76 & -21.87 & 21.87 & 0.64 & 0.89 & -0.10 & 0.09 & 0.92 & 1.55 & -1.16 & 1.16 & 0.84 \\
\hline JJA & 20.46 & -18.02 & 18.06 & 0.88 & 0.54 & -0.01 & 0.01 & 0.95 & 1.50 & -0.85 & 0.85 & 0.63 \\
\hline SON & 14.03 & -12.33 & 12.34 & 0.61 & 1.54 & -0.65 & 0.64 & 0.88 & 0.99 & -0.66 & 0.66 & 0.95 \\
\hline $\mathrm{F}$ & RMSE & B & MAE & $\rho_{p}$ & RMSE & B & MAE & $\rho_{p}$ & RMSE & B & MAE & $\rho_{p}$ \\
\hline DJF & 12.83 & -9.11 & 9.12 & 0.09 & 3.26 & -3.14 & 3.12 & 0.95 & 3.03 & -2.86 & 2.85 & 0.97 \\
\hline MAM & 22.73 & -20.88 & 20.89 & 0.67 & 1.41 & -1.18 & 1.17 & 0.94 & 2.91 & -2.70 & 2.70 & 0.82 \\
\hline JJA & 20.33 & -17.53 & 17.59 & 0.86 & 1.64 & -1.53 & 1.52 & 0.95 & 3.19 & -2.90 & 2.90 & 0.64 \\
\hline SON & 13.69 & -11.87 & 11.88 & 0.60 & 1.99 & -1.51 & 1.50 & 0.89 & 2.05 & -1.90 & 1.90 & 0.95 \\
\hline $\mathrm{G}$ & RMSE & B & MAE & $\rho_{p}$ & RMSE & B & MAE & $\rho_{p}$ & RMSE & B & MAE & $\rho_{p}$ \\
\hline DJF & 12.78 & -8.71 & 8.73 & 0.12 & 4.21 & -4.11 & 4.09 & 0.95 & 5.45 & -5.10 & 5.09 & 0.90 \\
\hline MAM & 24.58 & -22.51 & 22.52 & 0.58 & 2.24 & -2.07 & 2.06 & 0.94 & 5.43 & -4.95 & 4.95 & 0.08 \\
\hline JJA & 19.47 & -16.34 & 16.39 & 0.86 & 2.13 & -2.05 & 2.05 & 0.94 & 4.26 & -3.85 & 3.85 & 0.27 \\
\hline SON & 13.44 & -10.92 & 10.95 & 0.54 & 3.00 & -2.75 & 2.73 & 0.90 & 4.62 & -4.26 & 4.26 & 0.67 \\
\hline
\end{tabular}


NCEP-FNL data incorporates more observations, and is run at a higher resolution as compared to NNRP, and hence, results in more realistic simulations. The magnitude of the RMSEs, Bs, and MAEs, was also smaller for maximum and minimum temperatures as compared to A, except that minimum temperatures are now over-predicted rather than under-predicted.

Experiment D shows that using the BMJ scheme for cumulus/convective parameterisation rather than $\mathrm{KF}$, results in slightly higher RMSEs, Bs and MAEs for precipitation for all seasons as compared to A, with results for maximum and minimum temperatures being quite similar. Hence there is no apparent gain in using the BMJ scheme as compared to KF. Experiment E shows that using the RRTMG scheme for both longwave and shortwave radiation, results in no major differences in precipitation simulations as compared to A, but the RMSEs, Bs, and MAEs are lower for maximum and minimum temperatures. Use of CAM radiation on the other hand (Experiment F), does not result in markedly different results as compared to A. Hence, it appears that the RRTMG scheme should be preferred over the RRTM, CAM, and Dudhia schemes. Experiment G shows that using the ACM2 PBL scheme instead of the YSU scheme did not change precipitation simulations, but the RMSEs, Bs, and MAEs for maximum and minimum temperatures are now larger as compared to Experiment A. Hence, it appears that for the simulations considered here, the YSU scheme should be preferred over the ACM2 scheme.

Overall, the best model performance is achieved with Experiment D, as illustrated in Figure 1 showing the difference between WRF and AWAP. Precipitation is generally well simulated throughout the domain for all seasons, with the difference between observed and simulated precipitation ranging between -20 and $20 \mathrm{~mm} / \mathrm{month}$, except for localised higher over-prediction of 40-60 mm/month and under-prediction of $80 \mathrm{~mm} / \mathrm{month}$ at localised coastal areas during JJA. Precipitation during JJA is largely due to the passage of frontal systems, with precipitation being at its maximum at the coast and decreasing inland. Given the $10 \mathrm{~km}$ resolution of the WRF grid, and the $5 \mathrm{~km}$ resolution of the AWAP grid, it is possible that these large differences are due to the interpolation of the AWAP grid to the WRF grid. Maximum temperatures are generally well reproduced throughout the domain, with the differences being within an acceptable range of -3 to $2{ }^{\circ} \mathrm{C}$ throughout most of the domain, except for few localised regions of under-prediction below $-3{ }^{\circ} \mathrm{C}$. Minimum temperatures are also well reproduced with differences ranging from -2 to $3{ }^{\circ} \mathrm{C}$ throughout most of the domain.

\section{CONCLUSIONS}

A number of sensitivity tests were carried out with WRF-ARW model run over SWWA on a yearly timescale. It is found that using the NOAA weekly mean SSTs as compared to skin temperatures in NNRP did not result in markedly different results. However, using 6-hourly boundary conditions from the $1 \times 1$ degree NCEP-FNL (only available from July 1999 onwards), resulted in much smaller RMSEs, Bs, and MAEs, as compared to NNRP. This is expected given the higher resolution and level of data-assimilation of this product. Using the BMJ scheme for cumulus parameterisation resulted in slightly higher errors for precipitation and the RRTMG radiation scheme improved maximum and minimum temperature simulations as compared to the RRTM, Dudhia, and CAM schemes. Use of the ACM2 PBL scheme had little effect on precipitation simulations, but resulted in higher errors for maximum and minimum temperatures. Overall, the best model performance was by Experiment D, using the NCEP-FNL data as boundary conditions. However, more tests need to be carried out, by varying more than one setting as compared to the reference experiment. For example, using WRF3.3 with NCEP-FNL and RRTMG radiation. Additionally, experiments need to be carried out with different cloud micro-physics schemes, as this can have a strong influence on precipitation.

\section{ACKNOWLEDGEMENT}

This research is funded by the Australian Grains Research and Development Grant (MCV00013). All WRF simulations were supported by iVEC (http://www.ivec.org/) through the use of advanced computing resources provided by the Pawsey Super-Computing Center located at Murdoch University. B. J. Evans is supported by a Murdoch University research studentship. The AWAP soil moisture products were provided by Peter Briggs and Michael Raupach from the Commonwealth Scientific and Industrial Research Organisation division Marine and Atmospheric Research. NOAA_OI_SST_V2 data provided by the NOAA/OAR/ESRL PSD, Boulder, Colorado, USA, from their Web site at http://www.esrl.noaa.gov/psd/. 


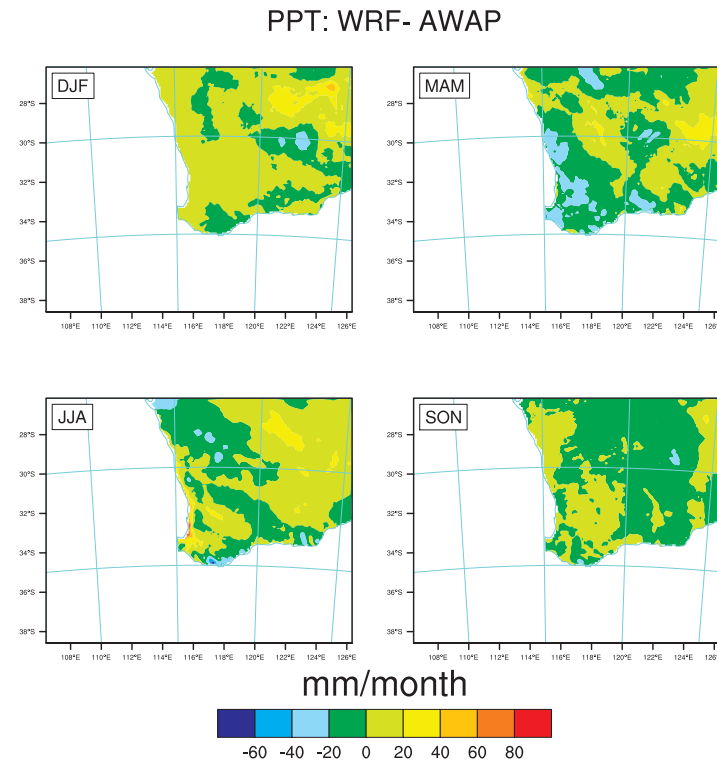

(a)

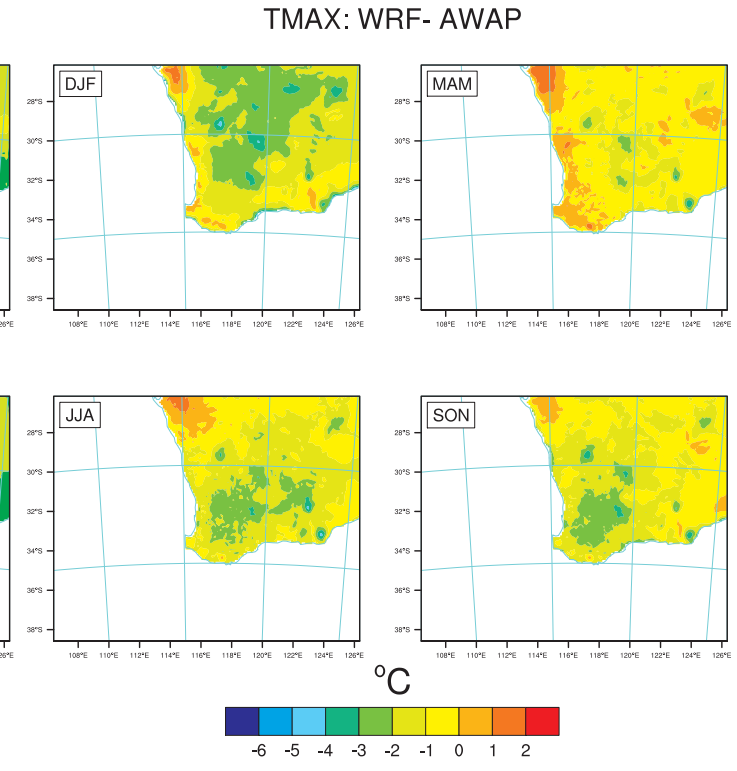

(b) TMIN: WRF- AWAP
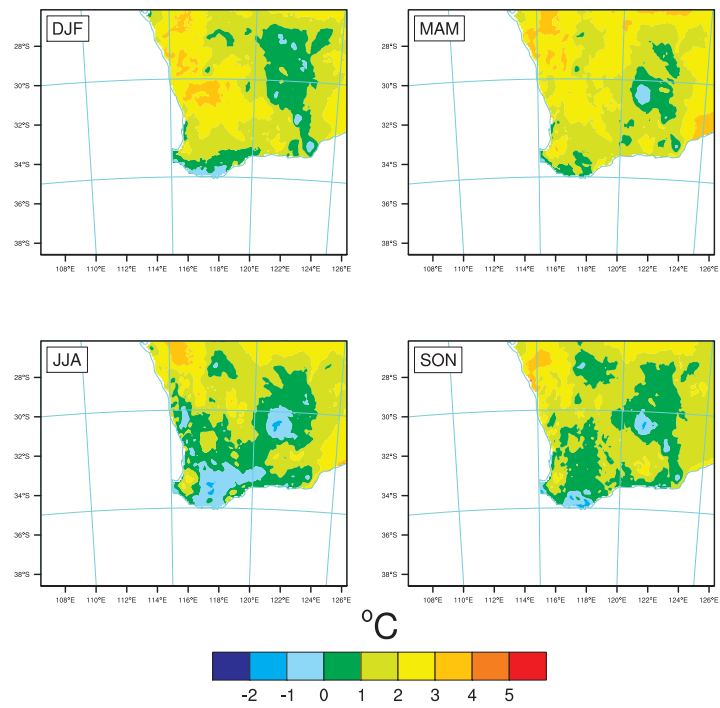

(c)

Figure 1. Difference in seasonal precipitation (PPT) (mm/month) and maximum and minimum temperatures (TMAX, TMIN) $\left({ }^{\circ} \mathrm{C}\right)$ between WRF and AWAP for Experiment D (Table 1). 
The NNRP and NCEP-FNL data for this study are from the Research Data Archive (RDA) which is maintained by the Computational and Information Systems Laboratory (CISL) at NCAR. NCAR is sponsored by the National Science Foundation (NSF). The original data are available from the RDA (http://dss.ucar.edu) in dataset number ds090.0 and ds083.2 respectively.

\section{REFERENCES}

Argzueso, D., J. M. Hidalgo-Munoz, S. R. Gamiz-Fortis, M. J. Esteban-Parra, J. Dudhia, and Y. CastroDiez (2011). Evaluation of WRF parameterizations for climate sutdies over Southern Spain using a multi-step regionalization. J. Climate, in press.

Bukovsky, M. S. and D. J. Karoly (2009). Precipitation simulations using WRF as a nested regional climate model. J. Appl. Meteor. Climatol. 48, 2152-2159.

Evans, J. P. and M. F. McCabe (2010). Regional climate simulation over Australia's Murray-Darling basin: A multitemporal assessment. J. Geophys. Res. 115, D14114.

Gallus, W. A. and J. F. Bresch (2006). Comparison of impacts of WRF dynamic core, physics package, and initial conditions on warm season rainfall forecasts. Mon. Wea. Rev. 134, 2632-2641.

Kalnay, E., M. Kanamitsu, R. Kistler, W. Collins, D. Deaven, L. Gandin, M. Iredell, S. Saha, G. White, J. Woollen, Y. Zhu, M. Chelliah, W. Ebisuzaki, W. Higgins, J. Janowiak, K. C. Mo, C. Ropelewski, J. Wang, A. Leetmaa, R. Reynolds, R. Jenne, and D. Joseph (1996). The NCEP/NCAR 40-year reanalysis project. Bull. Amer. Met. Soc. 77, 437-471.

Lo, J. C.-F., Z.-L. Yang, and R. A. Pielke (2008). Assessment of three dynamical climate downscaling methods using the Weather Research and Forecasting (WRF) model. J. Geophys. Res. 113, D09112.

Nauman, K. A., H. Truhetz, and A. Gobiet (2011). Parameterization-induced error characteristics of MM5 and WRF operated in climate mode over the Alpline region: An ensemble-based analysis. $J$. Climate 24, 3107-3123.

Raupach, M. R., P. R. Briggs, V. Haverd, E. A. King, M. Paget, and C. M. Trudinger (2008). Australian Water Availability Project. CSIRO Marine and Atmospheric Research, Canberra, Australia. http://www.csiro.au/awap. Accessed 22.10.2009.

Raupach, M. R., P. R. Briggs, V. Haverd, E. A. King, M. Paget, and C. M. Trudinger (2009). Australian Water Availability Project (AWAP): CSIRO Marine and Atmospheric Research Component: Final Report for Phase 3. CAWCR Technical Report No. 013. 67 pp.

Reynolds, R. W., N. A. Rayner, T. M. Smith, D. C. Stokes, and W. Wang (2002). An improved in situ and satellite sst analysis for climate. J. Climate 15, 1609-1625.

Skamarock, W. C., J. B. Klemp, J. Dudhia, D. O. Gill, D. M. Barker, M. G. Duda, X.-Y. Huang, W. Wang, and J. G. Powers (2008). A description of the advanced research WRF version 3. NCAR Tech. Note NCAR/TN-475+STR, 113 pp. 